
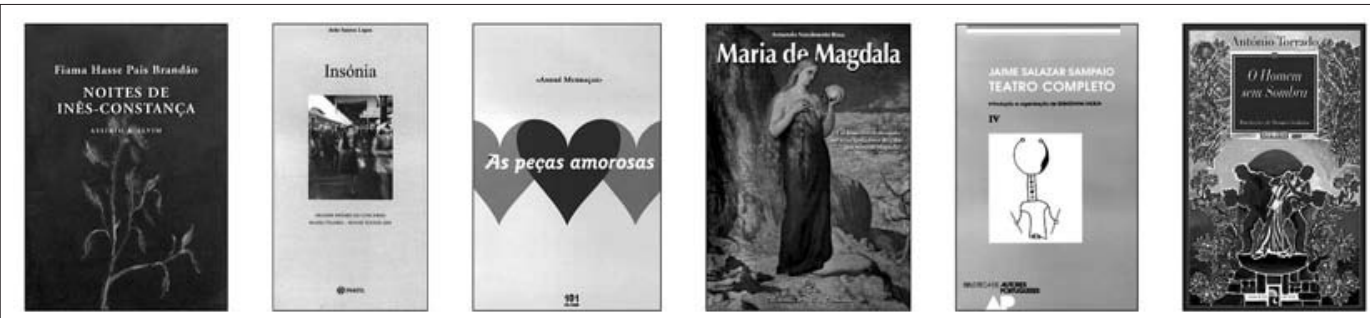

\title{
Publicações de teatro em 2005
}

\section{Lista compilada por Sebastiana Fadda}

\section{Peças originais (ou volumes de peças) em primeira edição}

AA.W., Teatro popular mirandês: Textos de cariz religioso, prefácio de José Oliveira Barata, Coimbra, GEFAC [Grupo de Etnografia e Folclore da Academia de Coimbra] / Almedina, 2005.

BOLITO, Carla, Transfer, Lisboa, 101 Noites, 2005.

BRANDÃO, Fiama Hasse Pais, Noite de Inês, Constança, posf. Eugénia Vasques, Lisboa, Assirio \&t Alvim, Obras de Fiama Hasse Pais Brandão, 1, 2005.

CALDAS, Miguel Castro, 0 homem do pé direito, 0 homem da picareta, Lisboa, Artistas Unidos / Livros Cotovia, Livrinhos de Teatro, 15, 2005.

- - Nunca-terra em vez de Peter Pan [inclui um CD com o registo áudio do espectáculo], Lisboa, Primeiros Sintomas Associação Cultural, 2005.

CAMÕES, Luis de, Teatro completo, pref., notas e fixação do texto de Vanda Anastácio, Porto, Caixotim Edições, Caixotim Clássicos, 2005

CARDOSO, Fernando, Alunos inteligentes, Lisboa, Portugalmundo, Teatro na Escola, 2005.

- - Bendito apagão, Lisboa, Portugalmundo, Teatro na Escola, 2005.

- - Diálogo com o principezinho, Lisboa, Portugalmundo, Teatro na Escola, 2005.

COELHO, Paulo Mira, Palhaço de mim mesmo, Lisboa, Hugin Editores, 2005.

EIRAS, Pedro, As sombras [Slow, A última praia antes do farol, Uma carta a Cassandra, O pressentimento de Inverno, Cultura], Porto, Campo das Letras, Campo do Teatro, 2005.

GUEDES, Castro, À esquerda do teu sorriso, Porto, Campo das Letras, Campo do Teatro, 2005.

HALPERN, Manuel, O segredo do teu corpo / Palco, Lisboa, Quimera, 2005.

JÚDICE, Nuno, Teatro [0 que eu te queria dizer, o que eu queria que me dissesses, Colóquio de amor, 0 crime perfeito, Área de serviço, O regresso de Fausto], Lisboa, Artistas Unidos / Livros Cotovia, Livrinhos de Teatro, 14, 2005

LA FÉRIA, Filipe, Canção de Lisboa, segundo o filme de Cottinelli Telmo, diálogos e versos de José Galhardo, música de Raúl Ferrão e Raul Portela, Mem Martins, Publicações Europa-América, 2005

LOPES, João Santos, Insónia, Lisboa, INATEL (Grande Prémio do Concurso INATEL/Teatro - Novos Textos 2005), 2005.
MENDONÇA, José Tolentino, Perdoar Helena, Lisboa, Assírio \&t Alvim, A Phala, 2005.

MURRAÇAS, André, As peças amorosas, Lisboa, 101 Noites, 2005.

PESSOA, Carlos J., A vida continua: Tragicomédia familiar em cinco actos, Lisboa, Livros da Garagem, 1, 2005.

- - 7 Crónicas de Natal para um autógrafo, Lisboa, Livros da Garagem, 2, 2005.

- - Ácido (sobre a imigração e talvez mais...), Lisboa, Livros da Garagem, 3, 2005.

POPPE, Manuel, A aranha: comédia sem actos, Lisboa, Teorema, 2005.

ROSA, Armando Nascimento, Maria de Magdala (fábula gnóstica), Lisboa, Parceria A.M. Pereira, 2005.

SAMPAIO, Jaime Salazar, Teatro completo IV [O veredicto, Lição de amor num aeroporto, A esperança, $A$ colecção, Pelos caminhos deste território, Algumas palavras numa sala de espera, A pista fechada], introd. e org. Sebastiana Fadda, textos de Maria Helena Serôdio, Georges Stobbaerts, João Lázaro, Daniel Gouveia, José Mascarenhas, Carlos Paniágua Fèteiro, Mário Primo e uma entrevista de Ana Maria Ribeiro, Lisboa, Imprensa Nacional-Casa da Moeda, Biblioteca de Autores Portugueses, 2005.

SARAMAGO, José, D. Giovanni ou o dissoluto absolvido, Lisboa, Editorial Caminho, 0 Campo da Palavra, 2005.

SOUZA, Naum Alves de, Teatro, Coimbra, Cena Lusófona | Associação Portuguesa para o Intercâmbio Teatral, 2005.

TORRADO, António, O homem sem sombra, Lisboa, Editorial Caminho, 2005.

\section{Peças em reedição}

BARBOSA, Miguel, Teatro [As multinacionais da bondade, O canário já não canta, A materialização do amor, versões revistasde Os carnivoros (1964), Muro alto (1967), A materialização do amor (1978)], Lisboa, Universitária Editora, 2005.

CAMÕES, Luis de, Obras Completas: Teatro, vol.I (Auto dos Anfatriões, Auto de El-Rei Seleuco, Auto de Filodemo), Lisboa, RBA Editores [adopta a lição estabelecida por Hernani Cidade em Círculo dos Leitores, 1984]. 


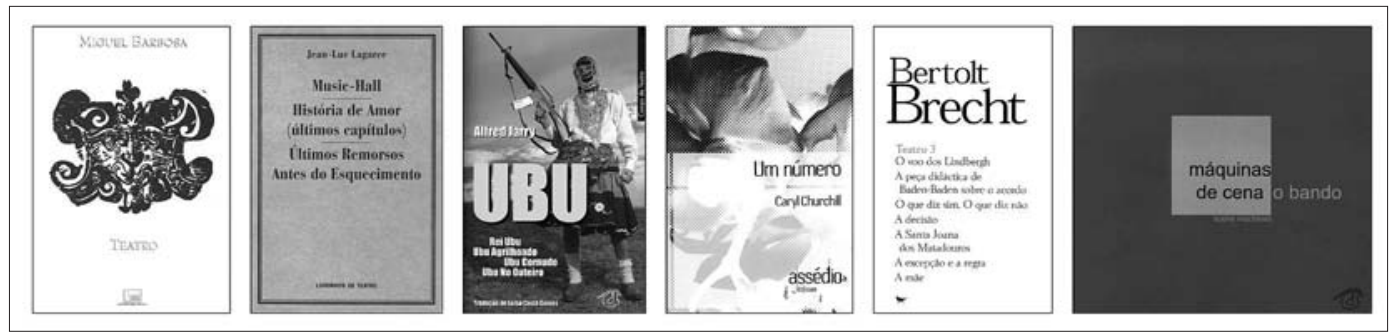

GARRETT, Almeida, Frei Luís de Sousa, realização didáctica de Luis Amaro de Oliveira, Porto, Porto Editora, 2005.

RÉGIO, José, Teatro, 2 vols. (1. . vol.: Jacob e o anjo, ou História do Rei e do bobo (1930-1931); Três máscaras, 1934; Sonho duma véspera de exame, 1935; Jacob e o Anjo, 1940; Sou um homem moral, inédito de 1940; Benilde ou a Virgem-mãe, 1947; $2 .{ }^{\circ}$ vol..: El-reiSebastião, 1949; 0 meu caso, 1950; A salvação do mundo, 1954; Três máscaras, 1957; Mário ou eu próprio - outro, 1957; O judeu errante, 1967; Apêndice: Post-fácio; Peça teatral - revista; 0 homem feliz; Fragmentos não identificados), pref. António Braz Teixeira, aparato crítico dos textos inéditos de Paula Estrela Lopes Mendes, Lisboa, Imprensa Nacional-Casa da Moeda, Biblioteca de Autores Portugueses / José Régio, Obra Completa, 2005.

RODRIGUES, Urbano Tavares, As torres millenárias, Mem Martins, Publicações Europa-América, 2005.

SILVA, António José da, Vida do grande D. Quixote de la Mancha e do gordo Sancho Pança (edição fac-similada da edição de 1905, Coimbra, França Amado-Editor, ópera jocosa prefaciada e revista por Mendes dos Remédios), Lisboa, Alcalá, 2005.

\section{Traduções}

BRECHT, Bertolt, Teatro 3 [0 voo dos Lindbergh, A peça didáctica de Baden-Baden sobre o acordo, 0 que diz sim. 0 que diz não, A decisão, $A$ Santa Joana dos Matadouros, A excepção e a regra, A mãe], trad. José Maria Vieira Mendes, Lino Marques, Manuel Resende, Jorge Silva Melo, introd. Vera San Payo de Lemos, Lisboa, Livros Cotovia, 3, 2005.

CHURCHILL, Caryl, Um número, trad. e introd. Paulo Eduardo Carvalho, Porto, Assédio Édissao, 2005.

DJERASSI, Carl / HOFFMAN, Roald, Oxigénio: Uma peça em dois actos e 20 cenas, trad. Manuel João Monte, pref. José Ferreira Gomes, Porto, Universidade do Porto, 2005.

FASSBINDER, Rainer Werner, Sangue no pescoço do gato, trad. José Maria Vieira Mendes, Lisboa, Edições Cotovia, Teatro, 2005.

HANDKE, Peter, Os insensatos estão a extinguir-se, trad. Patricia Link, pref. Guilherme Filipe, Lisboa, Alexandria Editores, 2005

HERZBERG, Judith, A fábrica de nada, trad. David Bracke, adapt. Miguel Castro Caldas, Lisboa, Artistas Unidos / Livros Cotovia, Livrinhos de Teatro, 13, 2005.

JARRY, Alfred, Ubu [Rei Ubu, Ubu agrilhoado, Ubu cornudo, Ubu no outeiro], trad. Luisa Costa Gomes, Porto, Campo das Letras, Campo do Teatro, 2005.

LACHAUD, Denis, Hetero, trad. José Paulo Moura, Porto, Moura Editor, 2005.
LAGARCE, Jean-Luc, Music-Hall, História de amor (últimos capitulos), Últimos remorsos antes do esquecimento, trad. Alexandra Moreira da Silva, Lisboa, Artistas Unidos / Livros Cotovia, Livrinhos de Teatro, 9, 2005. MAYORGA, Juan, Caminho do céu, 0 jardim queimado, Animais nocturnos, trad. António Gonçalves, Lisboa, Artistas Unidos / Atelier Européen de la Traduction, Scène Nationale d'Orléans / Livros Cotovia, Livrinhos de Teatro, 12, 2005.

MARBER, Patrick, Quase, trad. Vera San Payo de Lemos, Lisboa, Relógio d'Água, 2005.

PINTER, Harold / ONETTI, Antonio / TARANTINO, Antonio / SIERENS, Arne / ENIA, Davide / McLEAN, Ducan / WALSH, Enda / IUNKER, Finn / PRESNIAKOV, Irmãos / FOSSE, Jon / MENDES, José Maria Vieira / MAYORGA, Juan / RUSSO, Letizia / BARBOSA, Marcos / CALDAS, Miguel Castro / SCIMONE, Spiro, Conferência de imprensa e outras aldrabices, trad. Pedro Marques, Joana Frazão, Letizia Russo, José António Costa Ideias, José Maria Vieira Mendes, Jorge Silva Melo, Filipe e Nina Guerra, Pedro Porto Fernandes e António Gonçalves, Lisboa, Artistas Unidos / Teatro Nacional D. Maria II / Livros Cotovia, Livrinhos de Teatro, 2005.

RACINE, Jean, Berenice, trad. Vasco Graça Moura, ed. bilingue, Lisboa, Bertrand Editora, 2005.

- -, Fedra, trad. Vasco Graça Moura, pref. Maria Alzira Seixo, ed. bilingue, Lisboa, Bertrand Editora, 2005.

RUSSO, Letizia, Os animais domésticos, Túmulos de cães, trad. Jorge Silva Melo, José Lima e Pedro Marques, Lisboa, Artistas Unidos / Teatro Nacional D. Maria II / Livros Cotovia, Livrinhos de Teatro, 10, 2005.

SÓFOCLES, Filoctetes, trad., introd. e notas José Ribeiro Ferreira, Lisboa, Edições 70, Clássicos Gregos e Latinos, 2005.

TARANTINO, Antonio, Stabat mater, Paixão segundo João, trad. Tereza Bento, Lisboa, Artistas Unidos / Livros Cotovia, Livrinhos de Teatro 11, 2005.

TCHÉKHOV, Anton, 0 tio Vânia, trad. António Pescada, Porto, Campo das Letras, Campo do Teatro, 2005.

- -, 0 tio Vânia, trad. Nina Guerra e Filipe Guerra, Lisboa, Relógio d'Água, 2005.

WILDE, Óscar, Um marido ideal, trad. Carmo Vasconcelos Romão, Mem Martins, Publicações Europa-América, 2005.

\section{Estudos / Documentos}

AA.W., Companhia de Teatro de Sintra: 15 Anos a fazer caminho no teatro, s.l., Pinter Portuguesa, 2005.

AA.W., Teatro Animação de Setúbal: Histórias de teatro / 30 anos (1975-2005), Setúbal, TAS \&t DDLX, 2005. 


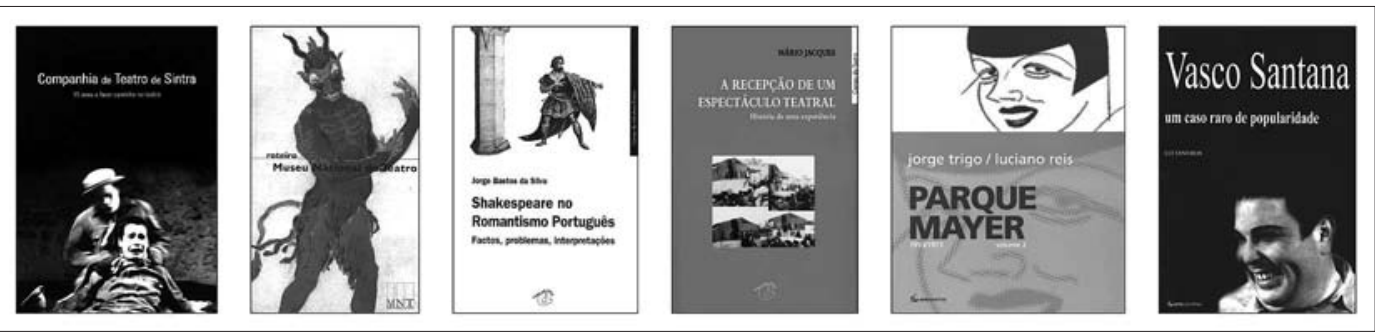

AA. W., Máquinas de cena / Scene Machines, Porto, Campo das Letras, Campo do Teatro, 2005.

ALVAREZ, José Carlos (editor), Museu Nacional do Teatro: Roteiro, contém textos de Luiz Francisco Rebello, Jorge Silva Melo, Mário Jacques, Vitor Pavão dos Santos, Ana Arez e José Carlos Alvarez, Lisboa, Museu Nacional do Teatro / Ministério da Cultura / Instituto Português de Museus, 2005. [tb. editado em inglês]

BORGES, Susana (org.), Desavergonhadamente pessoal: 0 trabalho dos actores, fotografias de Adriana Freire, Cruz Quebrada / Dafundo, Oficina do Livro, 2005.

CARVALHO, Mário Vieira de, A ópera como teatro: De Gil Vicente a Stockhausen, Porto, Âmbar, Col. Âmbar Referência, 2005

CRUZ, Duarte Ivo, Teatros de Portugal, Lisboa, Edições Inapa, História da Arte, 2005.

- - 0 essencial sobre Jaime Salazar Sampaio, Lisboa, Imprensa Nacional-Casa da Moeda, O Essencial Sobre, 2005.

- - O teatro português: estrutura e transversalidade, A Coruña, Biblioteca-Arquivo Teatral "Francisco Pillado Mayor" / Departamento de Galego-Português, Francês e Linguistica, 2005.

CRUZ, José de Matos, Joaquim de Almeida: Um actor de Montijo 1838-1921, Lisboa, Publicações D. Quixote, 2005.

DACOSTA, Fernando, José de Castro: Fotobiografia, Queluz, Mensagem, 2005.

FILIPE, Fernando / PRETO, Gonçalves (coord.), Armando Cortez: 1918-2002, Lisboa, Câmara Municipal de Lisboa, 2005.

GALHÓS, Cláudia, Corpo de cordas: 10 anos da Companhia Paulo Ribeiro, Lisboa, Assírio \&t Alvim, 2005.

GUERRA, Maria do Céu, Ser e não ser, ou estórias da história do teatro, Braga, Círculo de Leitores, 2005.

JACQUES, Mário, A recepção de um espectáculo teatral: História de uma experiência, Porto, Campo das Letras, Campo do Teatro, 2005.

LívIO, Tito, Ruy de Carvalho: Um actor no palco da vida, Lisboa, Novo Imbondeiro, 2005.

LOPES, Maria Virgílio Cambraia, 0 teatro n' A Paródia de Rafael Bordalo Pinheiro, Lisboa, Imprensa NacionalCasa da Moeda, Arte e Artistas, 2005.

LOURENÇO, Jorge Fazenda (ed.), A arte de Jorge de Sena [contém poesia, ficção, ensaio e teatro: 0 acto IV de O indesejado e Epimeteu ou o homem que pensava depois], Lisboa, Relógio d'Água, 2004.

MACHADO, João Nuno Sales, A imagem do teatro: Iconografia do teatro de Gil Vicente, Casal de Cambra, Caleidoscópio Edição e Artes Gráficas, 2005.

MELO, Maria do Céu de, A expressão dramática à procura de horizontes, Lisboa, Livros Horizonte, 2005.

MOUTINHO, José Viale, A história de William: A possivel infância de Shakespeare, ilustrações de José Emilio, Porto, Campo das Letras, 2005.

NASCIMENTO, Aires A. (ed.), Sófocles: XXV centenário do nascimento, Actas do colóquio, org. Centro de Estudos Clássicos da Faculdade de Letras da Universidade de Lisboa e Centro de Estudos Clássicos e Humanistícos da Faculdade de Letras de Coimbra, Lisboa, Centro de Estudos Clássicos, 2005.

NASCIMENTO, Aires A. / BARBOSA, Manuel de Sousa (coord.), Luis da Cruz, S.J. e o teatro jesuitico nos seus primórdios, Actas do colóquio comemorativo do IV centenário da morte do dramaturgo (1604-2004), Lisboa, Centro de Estudos Clássicos, 2005.

NIETZSCHE, Friedrich, A origem da tragédia, trad. Sofia Ribeiro, Mem Martins, Publicações Europa-América, 2005.

RAIMUNDO, Josefina, Fernando Curado Ribeiro: 0 último galã. Concerto para dois, Lisboa, Câmara Municipal de Lisboa / Rita Curado Ribeiro - Produções e Eventos, 2005.

REIS, Luciano, Teatros portugueses, Lisboa, SeteCaminhos, 2005.

- - Os grandes actores portugueses, Lisboa, SeteCaminhos, 2005.

- - Os grandes dramaturgos portugueses, Lisboa, SeteCaminhos, 2005.

- - Laura Alves, a rainha do palco, Lisboa, SeteCaminhos, 2005.

- - Vasco Santana, um caso raro de popularidade, Lisboa, SeteCaminhos, 2005

- - Expressão corporal e dramática, Lisboa, SeteCaminhos, 2005.

SANTOS, José Baião / LOBO, Fernando / PITÉ, Jorge., Dramaturgia [análise e debate teatral das peças $A$ orga, Réquiem para Sidónio e A carroça dos saltimbancos], vol. I, Lisboa, SeteCaminhos, 2005.

SILVA, Alexandra Moreira / CARVALHO, Paulo Eduardo (org.), Teatro em tradução: Cadernos de literatura comparada, n. ${ }^{\circ}$ 12/13, Porto, Edições Afrontamento / Instituto de Literatura Comparada Margarida Losa, 2005.

SILVA, Jorge Bastos da, Shakespeare no romantismo português: Factos, problemas, interpretações, Porto, Campo das Letras, Campo da Literatura / Ensaio, 2005.

SILVA, Maria de Fátima Sousa e, Ensaios sobre Eurípides, Lisboa, Livros Cotovia, Ensaio, 2005.

TEYSSIER, Paul, A língua de Gil Vicente, pref. de Ivo de Castro, trad. Telmo Verdelho, Evelina Verdelho, António José Miranda, Maria da Conceição Guerra, Maria Edite Ferreira, Eduardo Vasconcelos, Maria Helena Santana, José Manuel Pereira de Melo, Luis Machado de Abreu, Maria Leocádia Regalo, col. Ivo de Castro, Carlos Pio, José Camões e Helena Dias', Lisboa, Imprensa Nacional -. Casa da Moeda, 2005. 

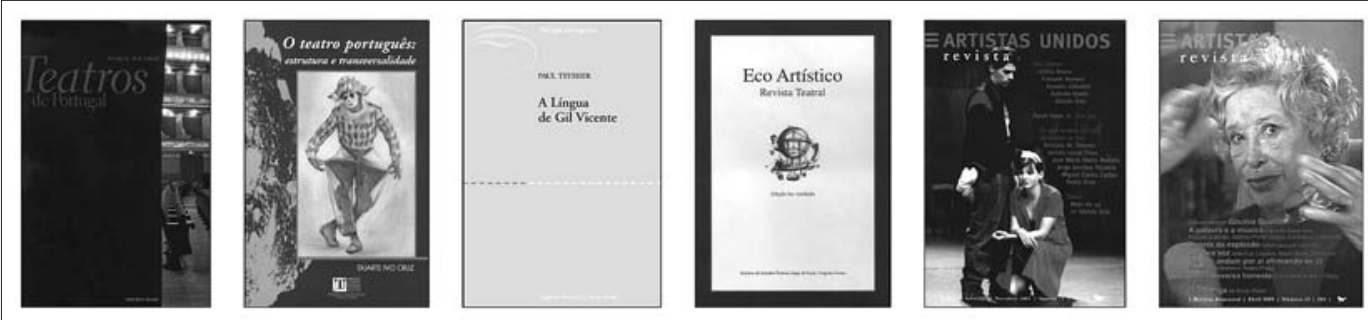

TRIGO, Jorge / REIS, Luciano, Parque Mayer 1953-1973, vol. 2, Lisboa, SeteCaminhos, 2005.

XAVIER, Lola Geraldes, Deleitar e instruir: A dramaturgia de Almeida Garrett, introd. José Oliveira Barata, Mangualde, Edições Pedago, 2005.

\section{Publicações periódicas}

Artistas Unidos: Revista, n. ${ }^{\circ} \mathrm{s} 13$ (Abril de 2005) e 14 (Novembro de 2005), dir. Jorge Silva Melo, Lisboa, Livros Cotovia.

Cena aberta, n. ${ }^{\circ} 4$ (Junho de 2005) e n. 5 (Dezembro de 2005), dir. António Augusto Barros, revista da Cena Lusófona, Coimbra.

Duas Colunas, n. ${ }^{\circ} \mathrm{s} 14$ (Janeiro de 2005) e 15 (Abril de 2005), dir. José Luis Ferreira, ed. João Luis Pereira, Porto, Teatro Nacional S. João.

Eco Artístico: Revista Teatral (10 de Outubro de 1911 a 30 de Dezembro de 1912), edição facsimilada, Coimbra, Instituto de Estudos Teatrais Jorge de Faria / Angelus Novus, 2005

Sinais de cena, n. 3 (Junho de 2005) e n. ${ }^{\circ} 4$ (Dezembro de 2005), dir. Maria Helena Serôdio, revista da Associação Portuguesa de Críticos de Teatro / Centro de Estudos de Teatro, Porto, Campo das Letras.

\section{PUBLICAÇÕES DE TEATRO EM 2003 e 2004}

\section{Adenda à lista publicada em Sinais de cena} n. ${ }^{\circ} \mathrm{s} 1$ e 3

ALMEIDA, J. Lopes de, Hotel Sarilhos: Comédia em 2 actos, Gondomar, Arca das Letras Editora, Teatro, 2004. [peça] CAETANO, Cristina Maia, Conhecer o teatro em Moçambique, Pinhel, PEL - Pinhel Editora, 2004. [estudo / documento] CÓRREGO, Manuel, Um desenho na face, Anailde, S. João da Madeira, 0 Regional Edições, 2004. [peça]

CORREIA, Júlia, Virgínia Vitorino e a vocação do teatro: Percurso de um sucesso, Amadora, Escola Superior de Teatro e Cinema, 2004. [estudo / documento]

LAROQUE, François, Shakespeare: 0 teatro do mundo, trad. Fernanda Oliveira, Lisboa, Quimera, Descobrir, 2003. [estudo / documento]

MOITA, Teixeira, Quanto durou Jacques?, (2. Prémio do Concurso INATEL/Teatro - Novos Textos 2002), Lisboa, INATEL, 2003. [peça]

MORAIS, José, A beleza e a felicidade: Fantasia cientifica Porto, Campo das Letras, Instantes de Leitura, 2003. [texto híbrido, entre a narrativa e a peça de teatro]

PLAUTO, A comédia dos burros, introd., trad. do latim e notas Aires Pereira do Couto, Lisboa, Edições 70, Clássicos Gregos e Latinos, 2003. [peça]

SANCHES, Vicente, Três aforismos (pré-póstumos, como diria Musil), Esta espécie de carta dirigida aos editores portuqueses para saber se querem editar as Obras Completas de Vicente Sanches; ou, pelo menos, as Incompletas, Castelo-Branco, Ed. do Autor, 2003. [peça]

- - A Rainha Santa e o Rei Poeta, peça de teatro de aforismos: Em sete aforismos e uma palavra inicial, Castelo-Branco, Ed. do Autor, 2004. [peça]

- - 21 Aforismos (mais ou menos teológicos). Teatro de aforismos: peça em três segmentos - Anexo mínimo ( A cada ser, Fábula das fábulas, 0 mágico, Cegos e escravos, A situação definitiva), Castelo-Branco, Ed. do Autor, 2004. [peça]

Adágio, Revista do Centro Dramático de Évora, n³8/39, dir. Cendrev, Setembro/Dezembro de 2004.

Cena aberta, n. 2 (Junho de 2004) e n. 3 (Dezembro de 2004), dir. António Augusto Barros, revista da Cena Lusófona, Coimbra. 